\title{
Erratum to: A review of decision-making approaches to handle uncertainty and risk in adaptive forest management under climate change
}

\author{
Rasoul Yousefpour • Jette Bredahl Jacobsen • \\ Bo Jellesmark Thorsen • Henrik Meilby • \\ Marc Hanewinkel • Karoline Oehler
}

Published online: 1 March 2012

(C) INRA / Springer-Verlag France 2012

\section{Erratum to: Annals of Forest Science}

DOI 10.1007/s13595-011-0153-4

In the Original article the Acknowledgement and the Funding sections have not been included.

To remedy this omission we print these details here.

Everything else in the paper remains correct.

Acknowledgments This study was conducted as part of the project "MOdels for AdapTIVE Forest Management" (MOTIVE).

Funding The present study was funded by the European Community's Seventh Framework Programme (FP7/2007-2013) under grant agreement $n^{\circ} 226544$.

The online version of the original article can be found at http://dx.doi. org/10.1007/s13595-011-0153-4.

R. Yousefpour $(\bowtie) \cdot$ J. B. Jacobsen · B. J. Thorsen $\cdot$ H. Meilby

Forest \& Landscape, University of Copenhagen,

Rolighedsvej 23,

1958 Frederiksberg C, Denmark

e-mail: ry@life.ku.dk

M. Hanewinkel

Eidg. Forschungsanstalt WSL,

Zürcherstrasse 111,

8903 Birmensdorf, Switzerland

K. Oehler

Regional Office EFICENT-OEF, European Forest Institute,

Wonnhaldestr. 4 ,

D-79100 Freiburg, Germany 